\title{
Management of pelviureteric junction obstruction at a tertiary teaching hospital in southwestern Nigeria: A retrospective analysis of case records
}

\author{
Ademola O. Talabi', Abdulkadir A. Salako', Oludayo A. Sowande', Tajudeen A. Badmus'1, Theophilus A. Aladekomo², \\ Rereloluwa N. Babalola', Chigozie I. Onyeze', Rotimi A. David', Olusanya A. Adejuyigbe' \\ 1. Department of Surgery, Obafemi Awolowo University Teaching Hospitals Complex, Ile-lfe, Nigeria \\ 2. Department of Paediatrics and Child Health, Obafemi Awolowo University Teaching Hospitals Complex, Ile-Ife, Nigeria \\ Correspondence: Dr Ademola O. Talabi (ademolatalabi1608@gmail.com)
}

(C) 2018 A.0. Talabi et al. This open access article is licensed under a (reative Commons Attribution 4.0 International License (http://creativecommons.org/licenses/by/4.0/), which permits unrestricted use, distribution, and reproduction in any medium, provided you give appropriate credit to the original author(s) and the source, provide a link to the Creative Commons license, and indicate if changes were made.

East Cent Afr J Surg. 2018 Apr;23(1):27-31 https://dx.doi.org/10.4314/ecajs.v23i1.6

\begin{abstract}
Background

Pelviureteric junction obstruction (PUJO) is an important cause of upper urinary tract obstruction. It can cause marked impairment of renal function, especially in bilateral cases, if not diagnosed and treated promptly. Surgical intervention is currently the mainstay of treatment. We aimed to review the pattern of presentation and management outcomes of patients diagnosed with PUJO.

\section{Methods}

We conducted a retrospective study of patients aged 2-60 years who presented with PUJO between January 2005 and December 2014. Demographic characteristics, clinical presentation, investigations, and treatment modalities were extracted from case notes. Data were analysed using SPSS version 20.

Results

The age range of the 32 included PUJO patients was 2-60 years, with a median age of 30 years. Children constituted 31\% of patients. There were 15 males and a male-to-female ratio of 0.88:1. Most PUJO was unilateral and left-sided $(n=19 ; 59 \%)$. Loin pain was the commonest symptom $(n=26 ; 81 \%)$, while $25 \%$ of patients had a urinary tract infection at presentation. All patients had normal renal function at the time of surgery, and Anderson-Hynes pyeloplasty was the most common technique employed (72\% of cases). Postoperatively, the majority of patients $(n=31 ; 97 \%)$ had complete symptom resolution. Surgical site infection $(n=3 ; 9 \%)$ was the commonest postoperative complication, and the median hospital stay was 11 days. There was no mortality.
\end{abstract}

\section{Conclusions}

Most patients with PUJO presented late. Most of our patients underwent Anderson-Hynes pyeloplasty with satisfactory outcomes.

Keywords: pelviureteric junction obstruction, PUJO, loin pain, Anderson-Hynes pyeloplasty, Foley Y-V plasty, Nigeria

\section{Introduction}

Pelviureteric junction obstruction (PUJO) refers to impairment of the normal transport of urine from the renal pelvis to the ureter. ${ }^{1}$ The pelviureteric junction (PUJ) is the most common site of obstruction along the upper urinary tract, ${ }^{2,3}$ and PUJO is the most common cause of hydronephrosis in children. ${ }^{4}$ Inadequate drainage of urine from the renal pelvis into the ureter results in hydrostatic distension of the renal pelvis and intrarenal calyces. The combination of raised intrapelvic pressure and stasis of urine in the collecting ducts results in progressive kidney damage and deterioration of renal function. ${ }^{5}$ Most cases are congenital in origin and are diagnosed prenatally in most developed countries. ${ }^{6}$ Inadequate canalization of the pelviureteric area, the premature arrest of ureteral muscular development, and a deficiency of interstitial cells of Cajal have been proposed as embryologic bases for this anomaly. ${ }^{7.8}$ Other possible causes include ureteral atresia, polyps, valves, extrinsic compression by aberrant early-branching lower pole vessels, retroperitoneal fibrosis, tumours, and ureteral stones. ${ }^{6,9,10}$

PUJO treatment has evolved from the open techniques to minimally invasive (endoscopic and laparoscopic) tech- 


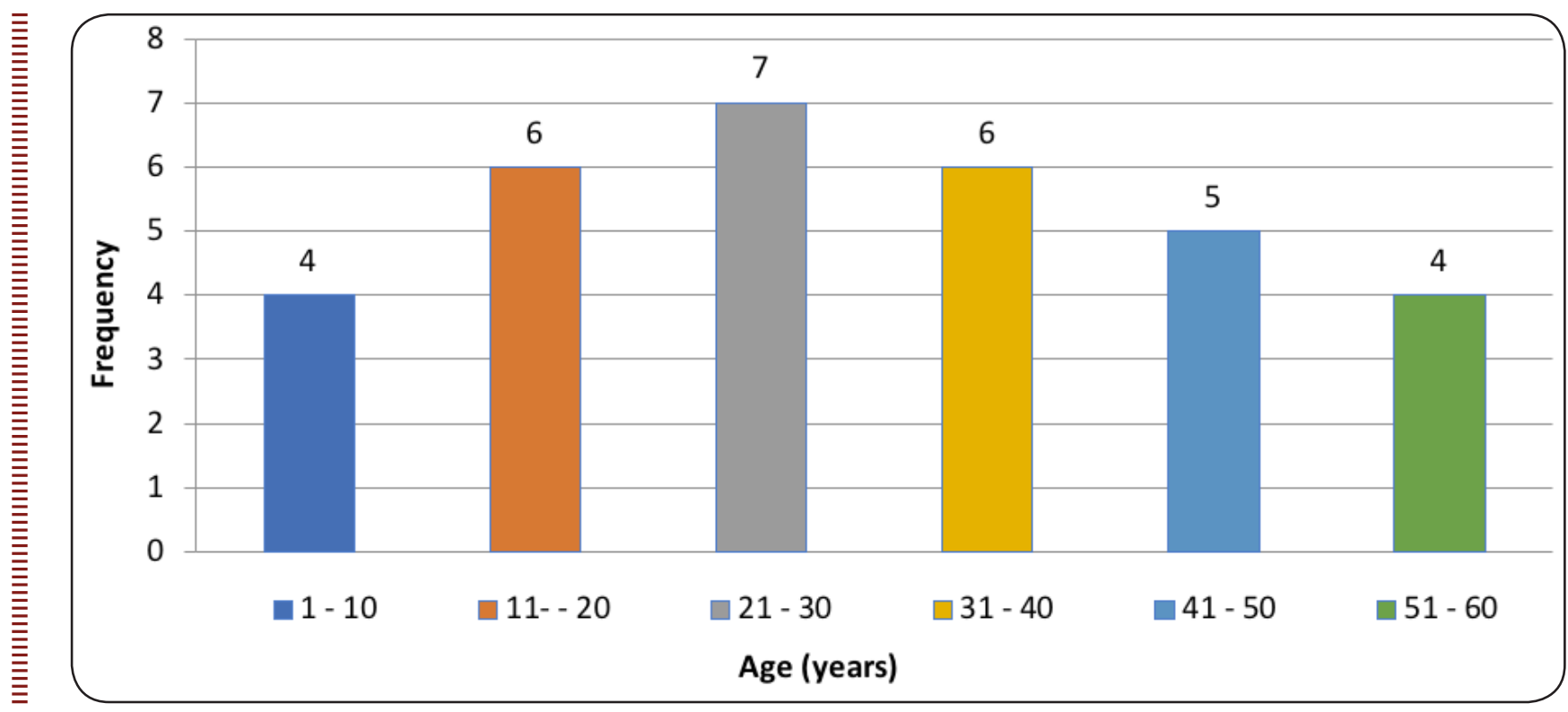

Figure 1. Patient age distribution

niques. The main techniques commonly employed in our environment are the Anderson-Hynes dismembered pyeloplasty and the Foley Y-V plasty. ${ }^{11-13}$

This article describes our experience with the management of PUJO at a Nigerian teaching hospital.

\section{Methods}

We reviewed the records of patients treated for PUJO from January 2005 to December 2014 at our centre. Clinical information was obtained from the medical records, theatre records, and ward registers. Data extracted included demographic characteristics, clinical presentation, and duration of symptoms. We also extracted results of relevant investigations, such as full blood count; electrolytes, urea, and creatinine; and urine microscopy, culture, and sensitivity. Information on abdominopelvic ultrasound, intravenous urography (IVU), computed tomography (CT) urogram, retrograde pyelogram, and treatment options were also retrieved. Patients were operated upon under general anaesthesia. Postoperative complications were documented. Serum electrolyte, urea, and creatinine measurements were repeated after surgery. Abdominopelvic ultrasound was carried out 4-6 weeks after surgery to assess and compare the degree of renal and the upper urinary tract dilatation. Double J stents were removed within 4-6 weeks after surgery. Patients were followed up for a period of 6 months to 2 years. Any record of persistent postoperative pain was identified from the case notes. For this study, children $\leq 6$ years of age were regarded as young children. We defined renal impairment as serum creatinine greater than $132 \mu \mathrm{mol} / \mathrm{L}$. Data obtained were analysed using SPSS version 20 (IBM Corp., Armonk, NY, USA) and results were expressed as means and percentages.

\section{Results}

Of the 42 patients that were surgically treated for PUJO at our centre during the study period, 32 records (76\%) were available for review. Patient age ranged from 2 to 60 years,
Table 1. Preoperative symptoms

\begin{tabular}{l|l}
\hline \multicolumn{1}{c|}{ Symptom } & \multicolumn{1}{c}{$\mathbf{n}(\%)$} \\
\hline \hline Loin pain & $26(81)$ \\
Recurrent fever & $10(31)$ \\
Nausea/vomiting & $6(19)$ \\
Loin swelling/mass & $8(25)$ \\
Haematuria & $1(3)$ \\
Failure to thrive & $1(3)$ \\
\hline
\end{tabular}

with a mean age of $28 \pm 17$ years and a median age of 30 years. The age distribution of patients is shown in Figure 1. There were 10 patients (31\%) younger than 15 years of age. Fifteen patients were male, and the male-to-female ratio was $0.88: 1$. Most of the children $(n=6 ; 60 \%)$, especially the younger ones, presented with an abdominal mass or abdominal swelling. One patient was asymptomatic, while symptom duration ranged from 1 month to 10 years in the symptomatic ones, with a mean duration of 2 years. The obstruction was on the left in 19 patients (59\%), on the right in 9 patients (28\%), and bilateral in 4 patients (13\%).

Loin pain was the commonest symptom $(n=26 ; 81 \%)$, while recurrent fever and loin swelling were found in 10 (31\%) and 8 patients (25\%), respectively. The symptom profile was as shown in Table 1. All patients had normal blood urea and serum creatinine preoperatively; 1 patient had leukocytosis. Eight patients (25\%) had a positive preoperative urine culture featuring gram-negative organisms (3 Klebsiella, 3 Escherichia coli, and 2 Pseudomonas). One patient (3\%) had concomitant nephrolithiasis.

All patients underwent abdominal ultrasound scanning, which showed hydronephrosis, marked pelvicalyceal dilatation, and sometimes cortical thinning in the ipsilateral kidneys. IVU was conducted on 25 patients (78\%). IVU findings 
Table 2. Intraoperative findings and procedures performed

\begin{tabular}{l|l}
\hline \multicolumn{1}{|c|}{ Intraoperative aetiologic findings } & \multicolumn{1}{|c}{$\mathbf{n}(\%)$} \\
\hline \hline Peri-ureteral adhesive bands & $6(19)$ \\
Lower pole aberrant vessels & $8(25)$ \\
Pelviureteric junction atresia & $17(53)$ \\
$\begin{array}{l}\text { Multiple pathologies (adhesive } \\
\text { band + lower pole vessel) }\end{array}$ & $1(3)$ \\
\hline Procedure & \\
\hline \hline $\begin{array}{l}\text { Anderson-Hynes pyeloplasty } \\
\text { Foley Y-V pyeloplasty } \\
\text { Simple nephrectomy } \\
\text { Intubated ureterotomy }+ \\
\text { nephrolithotomy }\end{array}$ & $23(72)$ \\
\hline
\end{tabular}

included enlarged hydronephrotic kidneys with pelvicalyceal dilatation, sharp indentation or a sharp cutoff of contrast at the PUJ, inability to identify the ureter, delayed contrast excretion, and non-excreting kidney. Six patients (19\%) who had non-excreting kidneys on IVU underwent retrograde ureteropyelography. CT urography was conducted on $5 \mathrm{pa}-$ tients (16\%), all of whom were adults being investigated for suspected malignancy.

The intraoperative aetiologic findings are shown in Table 2. All patients received either a double $\mathrm{J}$ stent $(\mathrm{n}=26 ; 81 \%)$ or a modified Cumming's catheter $(\mathrm{n}=6 ; 19 \%)$ for postoperative stenting. Hospital stay ranged from 5 to 31 days (median $=11$ days). There was no mortality.

Postoperative complications were seen in 6 patients (19\%) (Table 3). All patients had good postoperative renal function. During follow-up, symptom resolution was achieved for 31 patients (97\%); 1 patient (3\%) had persistent loin pain.

\section{Discussion}

The diagnosis of PUJO is made mostly in the third and fourth decades of life in most tertiary hospitals in Nigeria ${ }^{1,2,14}$ and other developing countries, ${ }^{15,16}$ as was seen in our study, which had a mean patient age of 30 years. In developed countries, almost all abnormalities of the PUJ are detected and treated early in life due to the widespread use of prenatal ultrasound and the advent of modern imaging techniques. ${ }^{17-19}$ None of the patients in our study were diagnosed prenatally even though ultrasound is readily available and the cost of prenatal ultrasound screening is relatively low. It is, therefore, not surprising that $31 \%$ of the patients in our study presented during childhood, even though this age of presentation is late compared to what is seen in developed countries. ${ }^{18,19}$ It appears that prenatal diagnosis will continue to elude most patients in developing countries until prenatal screening is incorporated into national healthcare policies.

In contrast to most studies, ${ }^{1,15,20}$ where a higher incidence of PUJO was reported in males, our series had a slight female
Table 3. Postoperative complications

\begin{tabular}{l|c}
\hline \multicolumn{1}{c|}{ Complication } & n (\%) \\
\hline \hline Wound infection & $3(9)$ \\
Postoperative pyelonephritis & $1(3)$ \\
$\begin{array}{l}\text { Sepsis and shunt malformation } \\
\text { (necessitating pyelostomy) }\end{array}$ & $1(3)$ \\
Incisional hernia & $1(3)$ \\
\hline
\end{tabular}

preponderance. This finding is, however, similar to findings from elsewhere, ${ }^{21-23}$ the explanation for the sex difference is unknown. PUJO has previously been reported to predominate on the left, and bilateral obstruction has been reported in $10 \%-40 \%$ of patients ${ }^{17,24}$; this also agrees with our findings.

In this study, as with other reports, ${ }^{3,16}$ the presenting complaints depended on patient age. We noted that young children tended to present with asymptomatic abdominal masses, while the older children and adults more commonly presented with loin pain. The most common symptom in our study was flank pain, and this concurs with other reports. ${ }^{1,2,21}$ The diagnosis of PUJO is confirmed principally by renal ultrasound, IVU, CT or magnetic resonance urography, diuretic isotope renogram, or retrograde ureteropyelography. In our study as well as in other published articles from developing countries, ${ }^{1,3,15}$ renal ultrasonography, IVU, retrograde ureteropyelography, and CT urography have been found valuable in assessing the degree of hydronephrosis, differential renal function, and also in defining the anatomical abnormality at the PUJ. It is also worth noting that CT urography was used to exclude renal malignancy in 3 patients in our study. The usefulness of renal isotope scanning in the diagnosis and management of PUJO cannot be overemphasized, as it allows for the determination of renal perfusion, differential renal function of each kidney, and the rate at which isotope leaves the renal pelvis. The differential renal function is said to be significant when it is $<40 \%{ }^{3,17}$ This percentage has been shown to correlate with the half-life washout curve. Mughal and colleagues ${ }^{3}$ observed that if renal isotope scanning shows PUJO in a kidney and the split renal function is $15-40 \%$, pyeloplasty should be performed. ${ }^{3}$ However, where the relative renal function is less than $20 \%$, it is better to give such kidneys a chance to recover after temporary relief of the obstruction with a percutaneous nephrostomy. Renal isotope scanning was not available at our facility during the study period, and this is a limitation of this study.

The most common cause of PUJO in our series was ureteral narrowing at the PUJ, followed by extrinsic compression by an aberrant lower pole vessel, and this agrees with the findings from elsewhere. ${ }^{1,15}$ This aberrant vessel could be the lower branch of the main renal vessel. Lee et al. observed that in about $40 \%$ of PUJO, an aberrant, accessory or early-branching lower pole vessel is found. ${ }^{17}$ This is much higher than the $25 \%$ observed in this study.

The goals of PUJO management are to improve urine 
flow, alleviate symptoms, and prevent further damage to the renal parenchyma, ultimately improving renal function. Open pyeloplasty is the comparative gold standard for PUJO treatment in children and adults, and Anderson-Hynes pyeloplasty is the most common method employed globally. ${ }^{2,3}$ The overall success rate is said to be between $90 \%$ and $100 \%{ }^{25,26}$ In our study, Anderson-Hynes dismembered pyeloplasty was performed in two-thirds of patients, with an overall success rate that is similar to that reported by other studies. ${ }^{1,3,15}$ Foley Y-V plasty was performed in a few patients because they had grossly distended and redundant renal pelves.

The surgical management of PUJO has evolved from the traditional open pyeloplasty, to endopyelotomy in selected patients, to laparoscopic pyeloplasty. More recently, robot-assisted laparoscopic pyeloplasty (RALP) (using the da Vinci Surgical System; Intuitive Surgical, Sunnyvale, CA, USA) has emerged as a minimally invasive treatment option for PUJO with several benefits over conventional laparoscopic pyeloplasty. These minimally invasive techniques have several advantages over open pyeloplasty: quicker recovery, shorter hospital stay, and fewer postoperative analgesic requirements. The outcomes of these minimally invasive procedures have been shown to compare favourably to open pyeloplasty. ${ }^{11-13,26}$

Four postoperative complications of pyeloplasty were encountered in our study. These were wound infection, py- elonephritis, shunt malfunction, and incisional hernia. One patient with wound infection was placed on parenteral antibiotics and daily wound dressing. The only patient who had pyelonephritis subsequently yielded a urine culture that grew E. coli sensitive to cefuroxime. The patients with shunt malfunction and incisional hernia, respectively, underwent shunt removal via cystoscopy and herniorrhaphy 11 months after pyeloplasty. The various postoperative complications noted in this study compare favourably with those encountered in other studies. ${ }^{3,21}$ Abdominal ultrasonography repeated 4-6 weeks after surgery revealed significant relief of obstruction in all patients. In our series, the majority of the patients had satisfactory renal function and were symptom-free postoperatively except for 1 patient who experienced persistent pain. We found this to be in tandem with other reports. ${ }^{1,3,15}$

\section{Conclusions}

Most of our patients with PUJO presented late. Prenatal ultrasound and a high index of suspicion are desirable for early detection and treatment. Anderson-Hynes open pyeloplasty remains our treatment of choice because of its effectiveness and associated low complication rate.

\section{Competing interests}

All authors declare that they have no competing interests related to this work.

\section{References}

1. Takure AO, Adebayo SA, Sotunmbi PT, Okeke LI, Olapade-Olaopa EO, Shittu OB. Pelvi-ureteric junction obstruction in adults in a resource limited environment: causes, features and outcome of treatment. Niger J Surg Res. 2015;16(1):159. doi: 10.4103/1595-1103.166885.

2. Obarisiagbon EO, Agbugui JO. Outcome of delayed presentation of pelvi-ureteric junction obstruction. Afr J Med Health Sci 2014;13(1):11-4. doi: 10.4103/23845589.139436

3. Mughal SA, Soomro S. Pelvi-ureteric junction obstruction in children. J Surg Pak Int. 2008 Oct;13(4):163-6.

4. Thomas DF. Prenatally diagnosed urinary tract abnormalities: long-term outcome. Semin Fetal Neonatal Med. 2008 Jun;13(3):189-95. doi: 10.1016/j. aju.2013.06.003. Epub 2007 Nov 26

5. Traxel EJ, Caplen DE. Ureteral obstruction and malformations. In: Ashcraft KW Holcomb GW, Murphy JP, editors. Pediatric surgery. 4th ed. Philadelphia: Elsevier Saunders; 2005. p. 732-47.

6. Ankara SY, Hsu THS. Management of upper urinary tract obstruction. In: Kavoussi LR, Novick AC, Partin AW, Peters CA, editors. Campbell-Walsh urology. 10th ed. Philadelphia: Elsevier Saunders; 2012. p. 1122-47.
7. Ruano-Gil D, Coca-Payeras A, TejedoMateu A. Obstruction and normal recanalization of the ureter in the human embryo. Its relation to congenital ureteric obstruction. Eur Urol. 1975;1(6):287-93.

8. Solari V, Piotrowska AP, Puri P. Altered expression of interstitial cells of Cajal in congenital ureteropelvic junction obstruction. J Urol. 2003 Dec;170(6 Pt 1):2420-2. doi: 10.1097/01. ju.0000097401.03293.f0.

9. Maizels, M, Stephens F.Valves of the ureter as a cause of primary obstruction of the ureter: anatomic, embryologic and clinical aspects. JUrol 1980; 123:742-747.

10. Stephens FD. Ureterovascular hydronephrosis and the "aberrant" renal vessels. JJ Urol. 1982 Novi128(5):984-7. doi: 10.1016/ S0022-5347(17)53308-X

11. Anderson JC, Hynes W. Retrocaval ureter a case diagnosed pre-operatively and treated successfully by a plastic operation. Br J Urol. 1949 Sep:21(3):209-14. doi: 10.1111/j.1464-410X.1949.tb10773.x.

12. Streem SB. Ureteropelvic junction obstruction. Open operative intervention. Urol Clin North Am. 1998 May;25(2):331 41. doi: 10.1016/S0094-0143(05)70022-7.
13. Schuessler WW, Grune MT, Tecuanhuey LV, Preminger GM. Laparoscopic dismembered pyeloplasty. J Urol. 1993 Dec;150(6):1795-9. doi: 10.1016/S00225347(17)35898-6.

14. Ibrahim AG, Aliyu S, Ali N. Bilatera pelvi-ureteric junction obstruction: our experience in a developing country. Niger J Clin Pract. 2014 May-Jun;17(3):267-9. doi: 10.4103/1119-3077.130205.

15. Hounnasso P, Georges Avakoudjo J, Yde Soumanou F, Djidjoho G, Agounkpe $M$, Natchagande $G$, et al. Evaluation of the management results of ureteropelvic junction abnormalities. Open J Urol. 2015:5(9):167-71. doi: 10.4236/ oju.2015.59026

16. Tayib AM. Long term results of pyeloplasty in adults Saudi Med J. 2004 Mar.25(3):3636.

17. Lee HY, Han SW. Ureteropelvic junction obstruction: what we know and what we don't know. Korean J Urol. 2009 May:50(5):423-31. doi: 10.4111/ kju.2009.50.5.423.

18. Moreira-Pinto J, Osório A, Vila F, de Castro $J$, Réis A. Dismembered pyeloplasty for ureteropelvic junction syndrome treatment in children. Afr J Paediatr Surg. 2012 May-Aug;9(2):98-101. doi: 10.4103/0189-6725.99392. 
19. Braga LH, Liard A, Bachy B, Mitrofanoff P. Ureteropelvic junction obstruction in children: two variants of the same congenital anomaly? Int Braz J Urol. 2003 Nov-Dec;29(6):528-34. http://dx.doi. org.10.1590/S1677.55382003000600010.

20. Maranya GA, Oduor PR. Pelviureteric junction obstruction: a surgical experience. East Cent Afr J Surg. 2004;9(2):21-4.

21. Ramyil VM, Dakum NK, Ogwuche El. The management of upper urinary tract obstruction in resource-poor settings. Afr J Urol. 2008;13(1):30-6.
22. Thom MR, Haseebuddin M, Roytman TM, Benway BM, Bhayani SB, Figenshau RS. Robot-assisted pyeloplasty: outcomes for primary and secondary repairs, a single institution experience. Int Braz J Urol. 2012 Jan-Feb;38(1):77-83.

23. Siqueira TM Jr, Nadu A, Kuo RL, Paterson RF, Lingeman JE, Shalhav AL. Laparoscopic treatment for ureteropelvic junction obstruction. Urology. 2002 Dec;60(6):9738. doi: 10.1016/S0090-4295(02)02072-1.

24. Carr MC, El-Ghoneimi A. Anomalies and surgery of the ureteropelvic junction in children. In: Wein AJ, Kavoussi LR, Novick AC, Partin AW, Peter CA, editors. CampbellWalsh urology. 9th ed. Philadelphia: Saunders; 2007. p. 3359-82.
25. Nerli RB, Reddy MN, Jali SM, Hiremath MB. Preliminary experience with laparoscopic Foley's YV plasty for ureteropelvic junction obstruction in children. J Minim Access Surg. 2014 Apr;10(2):72-5. doi: 10.4103/0972-9941.129953.

26. Nour H, Mostafa A, Gobashy S, Elganzoury H, Elkholy A, Riad E. Laparoscopic management of primary pelvi-ureteric junction obstruction: single-centre experience. Arab J Urol. 2011 Dec;9(4):2414. doi: 10.1016/j.aju.2011.10.005. Epub 2011 Nov 12. 